\title{
O STORIFY E O JORNALISMO CIDADÃO NA INTERNET
}

\author{
Daniele Ferreira Seridório, Caroline Kraus Luvizotto
}

Universidade Estadual Paulista “Júlio de Mesquita Filho" - UNESP. Programa de Pós-Graduação em Comunicação, Presidente Prudente - SP. E-mail: seridorio@gmail.com

\section{RESUMO}

Este estudo pretende compreender os potenciais democráticos e sociais do jornalismo cidadão na internet e como o Storify pode servir de ferramenta para atingir este fim. O problema concentrase em analisar o uso desta ferramenta por empresas de mídia para verificar a efetiva pluralidade das temáticas ou somente um reforço do agendamento que já ocorre nas versões tradicionais da notícia. A pesquisa utiliza a metodologia de análise de conteúdo para observar como três empresas midiáticas utilizam o Storify: jornal O Estado de São Paulo, jornal Zero Hora e revista Veja. Os resultados baseiam-se nas temáticas mais recorrentes que foram dividas em sete categorias: polícia; política; cidade; esporte; tecnologia; ciência e mídia. Esta análise permitiu concluir que em relação à temática o jornal O Estado de São Paulo foi, entre os veículos analisados, o mais plural, depois o jornal Zero Hora, e por fim, a revista Veja.

Palavras-chave: Jornalismo cidadão, Internet, Storify, Inteligência coletiva.

\section{STORIFY AND ONLINE CITIZEN JOURNALISM}

\begin{abstract}
This study aims to understand the democratic and social potential of online citizen journalism, and how Storify can be use as a tool to achieve this goal. The focus is to analyse the use of this tool by media companies to verify if there are plurality of themes, or if there are gatekeeping of the information - such as occur in traditional media. The research will use the content analyse methodology to observe how three media companies use the website Storify: $O$ Estado de São Paulo, Zero Hora and Veja. The results are based on the most frequent themes, which were divided into seven categories: police; politics; city; sport; technology; science and media. With this analyse we were able to concluded that, according to the theme, O Estado de Sao Paulo had, between the media companies analysed, the most plural approach, after it is Zero Hora, and lastly Veja.

Keywords: citizen journalism, internet, Storify, collective intelligence.
\end{abstract}




\section{CONSIDERAÇÕES INICIAIS: CONSTRUÇÃO COLETIVA E JORNALISMO CIDADÃO}

A sociedade se organizou de tal maneira no ciberespaço que a configuração das comunidades virtuais fez surgir universos de relação e de compartilhamento de informações; os tradicionais meios de comunicação não representam mais o centro dissipador da informação. A internet não é somente um fenômeno técnico, ela configura-se também como um movimento social.

A forma de consumir conteúdo mudou diante do deslocamento do eixo central de disseminação da informação. A grande mídia perdeu parte do monopólio e divide espaço na rede com blogs e portais de conteúdos alternativos. Os meios tradicionais, inseridos na web competem com pessoas que não tinham acesso à produção de conteúdo, o leitor se vê agora em um ambiente onde ele pode consumir e produzir.

Os impérios monolíticos de meios de comunicação de massa estão se dissolvendo em uma série de indústrias de fundo de quintal [...] os atuais barões das mídias irão se agarrar a seus impérios centralizados amanhã, na tentativa de mantê-los (JENKINS, 2009, p. 32).

A utilização da internet como veículo de comunicação ampliou o sentido de jornalismo cidadão. Já que com um computador doméstico ligado à rede, indivíduos tem poder de produção, edição e veiculação de conteúdo, criando, desta maneira, uma cultura da colaboração em rede.

A dimensão participativa do jornalismo pode ser caracterizada de maneira ampla, pela criação e implementação em diferentes etapas do processo de coleta, criação, análise e distribuição e notícias. A forma de compartilhar informações tem ser mostrado bastante variável em diferentes sistemas de comunicação participativos, como fóruns, blogs e sites de tipo open source. Em maior ou menor medida, o jornalismo se transforma a medida que o fenômeno colaborativo cresce (HOLANDA, PALACIOS, QUADROS e SILVA, 2008, p.57)

As características da web atual trouxeram uma nova realidade aos meios de comunicação, cujo ponto chave é a interatividade. A possibilidade de interação na construção da informação modifica a recepção do conteúdo e relação entre consumidor e produtor.

Ademais, a internet possibilitou a existência de sites e sistemas de informação que funcionam pela colaboração os usuários na publicação, troca e avaliação de conteúdos. Essas plataformas, classificadas como meios sociais ou meios cidadãos (MILANI, 2008), são administradas, autorreguladas, moderadas, comentadas, produzidas e editadas pelos próprios usuários. "A universalidade da linguagem digital e pura lógica das redes do sistema de comunicação geraram as condições tecnológicas para a comunicação global horizontal" (CASTELLS, 2008, p 82). 
Os modelos de criação coletiva do conteúdo deveriam tecer uma teia de comunicação horizontal, na qual não há poderes ou hierarquia na seleção de conteúdos, somente uma organização do que está no ciberespaço. Dentro desta perspectiva questiona-se se é possível conceber um jornalismo plural e participativo, ou se as ferramentas existentes, que sugerem uma rede de colaboração, controlam o conteúdo de acordo com seu posicionamento editorial.

Surgem, então, conceitos de jornalismo cidadão, que diferentemente do que o nome possa vir a sugerir, não restringe o tema do que é noticiado, mas sim a forma de produção envolvida.

As interfaces impulsionam a participação e o compartilhamento inibindo o consumo meramente contemplativo formador de fãs e audiências. Se a globalidade se definia como a submissão de uma totalidade aberta e irrefreável às regulações conservadoras da preservação e do consenso; a participação e o compartilhamento se revelam os novos fundamentos para a construção de uma mundialização ativa e afirmativa das singularidades de sua vasta multidão (ANTOUN; MALINI, 2013, p. 06)

Para Foschini e Taddei (2006) o conceito de jornalismo cidadão se desmembra em mais quatro conceitos: Jornalismo Participativo, Jornalismo Colaborativo, Jornalismo Código Aberta e Jornalismo Grassroots. Essas modalidades, na medida em que expõe diferentes angulações dos fatos, ajudam a criar um cenário plural de compreensão das notícias.

O termo "jornalismo cidadão" foi adotado em todo o mundo e também no Brasil para nomear a produção de notícias nesse novo universo. Ele não exclui a produção dos jornalistas profissionais, acrescenta a ela a contribuição de cidadãos jornalistas, leigos que são testemunhas de fatos importantes, gente que está no lugar certo e na hora certa para cobrir um evento, especialistas que podem falar melhor sobre determinado assunto e ainda todas as vozes que simplesmente desejam se manifestar (FOSCHINI, TADDEI, 2006, pp. 10-11).

A configuração em rede da Internet oferece ferramentas ideias para a construção de plataformas de jornalismo cidadão. "Technology has given us a communications toolkit that allows anyone become a journalist at little cost and, in theory, with global reach. Nothing like this has ever been remotely possible before"(GILLMOR, 2004, p. 12).

Neste sentido, este estudo pretende compreender os potenciais democráticos e sociais do jornalismo cidadão na internet e como o Storify pode servir de ferramenta para atingir este fim. A pesquisa utiliza a metodologia de análise de conteúdo para observar como três empresas midiáticas utilizam o Storify: jornal O Estado de São Paulo, jornal Zero Hora e revista Veja, estudando o uso desta ferramenta por essas empresas de mídia para verificar a efetiva pluralidade 
das temáticas ou somente um reforço do agendamento que já ocorre nas versões tradicionais da notícia.

\section{O STORIFY}

O Storify é um meio cidadão que permite que qualquer pessoa cadastrada publique textos a respeito do assunto que desejar. O seu diferencial é na construção do texto. O usuário dispõe, para escrever, de uma caixa para o título, uma para o texto e de um sistema de busca, que permite que ele pesquise o tema sobre o qual está escrevendo, filtrando por redes sociais - facebook, twitter, instagram e etc. Os resultados desta pesquisa podem ser colocados entre os parágrafos do texto, de modo a ampliar ou explicar a discussão.

A ideia é utilizar o discurso e o conhecimento que já está na internet como insumo de criação. Assim, aproveita-se uma das características da internet definidas por Lévy, a inteligência coletiva.

A inteligência coletiva para Pierre Lévy (1998) está distribuída por toda parte, é o conhecimento da humanidade, que não está armazenado em um local. Jenkins destaca os processos sociais envolvidos na construção desta inteligência. "O que consolida uma inteligência coletiva [...] (é) o processo social de aquisição do conhecimento, que é dinâmico e participativo -, continuamente testando e reafirmando os laços socais do grupo social" (JENKINS, 2009, p. 88).

Universidades, meios de comunicação, órgãos governamentais e cidadãos utilizam seus perfis na ferramenta Storify para, a partir da inteligência coletiva criar textos baseados nos princípios do jornalismo cidadão.

No lugar de uma criação que resulta em um objeto pronto, com as novas tecnologias da informação, verificamos a emergência do processo colaborativo entre grupos para criar um trabalho, performance, evento ou projeto. Dentro da lógica de criação colaborativa, opera um modo de trabalho baseado na coleta, na classificação e na associação dos trabalhos pré-existentes, dentro de um universo bastante variado. Nesse sentido, criar e reunir fragmentos de estéticas disponíveis para que se atribua a estes novos significados e valores (MALINI, 2008, p.3).

Os conhecimentos compartilhados nas redes sociais são o insumo de produção do Storify, que o utiliza para criações e recriações, gerando um conhecimento em escala crescente. O Storify dá ao usuário o poder de organizar as informações dissipadas pelo ciberespaço, organizando, reorganizando e podendo dar novos sentidos a ela.

Acontecimentos, decisões, ações e pessoas estariam situados nos mapas dinâmicos de um contexto comum e transformariam continuamente o universo 
virtual em que adquirem sentido. Nessa perspectiva, o ciberespaço torna-se-ia o espaço móvel das interações entre conhecimentos conhecedoras de coletivos inteligentes desterritorializados (LÉVY, 1994, p. 29).

A utilização do Storify por empresas de mídia, porém, pode ser questionada na medida em a seleção do conteúdo feita por esses usuários pode funcionar como um seletor antidemocrático da informação, contrariando a essência da pluralidade da participação e gerando agendamento e gatekeeping

The pace of technological change, in areas such as wireless data and peer-topeer technologies, keeps some pressure on the control freaks. So much has changed, but the underlying premises of We the Media have not. I think we're in the early days of something quite wonderful - maybe even a little frightening - a time when the people may be able to regain control of news. [...] If this goes well, we'll move into a new era of media literacy and what we might call news activism. To the extent that people become engage with events around them, an especially to the extend that they become journalistic activists, they will be making better citizens of themselves. Tomorrow needs them (GILLMOR, 2004, p. 18).

Pensando o Storify como uma ferramenta de pluralidade da notícia é importante vigiar o uso que as empresas midiáticas fazem desta ferramenta, uma vez que ele pode ser pensado como uma vitrine do que é dito a respeito de determinado tema na internet, pois parte do princípio do enlaçamento de discursos. O jornal O Estado de São Paulo, o jornal Zero Hora e a revista Veja possuem perfis no Storify, que utilizam, normalmente, para corroborar assuntos em pauta em determinado momento e mostrar a opinião dos usuários de mídias sociais sobre os temas.

Para a análise optamos pela metodologia da análise de conteúdo a partir das seguintes categorias: temáticas mais recorrentes, uso das fontes, e construção da cidadania. Este artigo, contudo, compreende os resultados de análise da primeira categoria, já que o trabalho ainda está em desenvolvimento. $\mathrm{O}$ corpus utilizado neste artigo é representado pelos textos publicados no período de um mês pelos veículos, que compreende de 15 de maio de 2014 a 15 de junho de 2014.

\section{ANÁLISE DAS TEMÁTICAS}

O estudo quantitativo das temáticas mais recorrentes podem revelar graus de agendamento da notícia. As temáticas serão dividias pelas seguintes categorias: polícia; política; cidade; esporte; tecnologia; ciência; e mídia. 
No período do recorte temporal desta análise, os três veículos publicaram 19 histórias, sendo uma de Veja, dezesseis de O Estado de São Paulo e duas do Zero Hora. Em números gerais, as manchetes foram dividas da seguinte maneira: 6 de cidade; 5 de esporte; 4 de tecnologia; uma de ciência; uma de mídia; uma de polícia; e uma de política.

Tabela 1. Análise descritiva dos dados

\begin{tabular}{|c|c|c|}
\hline Veículos & Manchete & Temática \\
\hline Veja & Os tuites de Miguel Nicolelis & Tecnologia \\
\hline \multirow[t]{16}{*}{$\begin{array}{l}\text { O Estado de São } \\
\text { Paulo }\end{array}$} & $\begin{array}{l}\text { Nas redes sociais, internautas comemoram recuperação de } \\
\text { Schumacher }\end{array}$ & Esporte \\
\hline & $\begin{array}{l}\text { Internautas comentam playback de cantores na abertura da } \\
\text { Copa }\end{array}$ & Esporte \\
\hline & Internautas repercutem exoesqueleto & Ciência \\
\hline & $\begin{array}{l}\text { Internautas reclamam de erro no Facebook que impede } \\
\text { publicação de fotos }\end{array}$ & Tecnologia \\
\hline & $\begin{array}{l}\text { Greve no Metrô SP: Internautas comentam 5o dia de } \\
\text { paralisação }\end{array}$ & Cidade \\
\hline & SP tem manhã mais lenta de história & Cidade \\
\hline & SP: Internautas relatam problemas no trânsito e metrô & Cidade \\
\hline & 10 dia de greve sem metrô em SP & Cidade \\
\hline & $\begin{array}{l}\text { Greve no metrô em SP: internauta contam a situação das } \\
\text { estações, ônibus e trânsito }\end{array}$ & Cidade \\
\hline & Internautas comentam venda de ingressos da Copa & Esporte \\
\hline & Site no novo Estado rende elogios nas redes sociais & Tecnologia \\
\hline & $\begin{array}{l}\text { Joaquim Barbosa deixará o STF: NAS Veja repercussão nas } \\
\text { Redes sociais }\end{array}$ & Política \\
\hline & $\begin{array}{l}\text { Moradores do Complexo Alemão denunciam nas redes } \\
\text { sociais tiroteio }\end{array}$ & Polícia \\
\hline & Ônibus não circulam em salvador nesta terça-feira & Cidade \\
\hline & Whatsapp: usuários reclamam de falha no aplicativo & Tecnologia \\
\hline & Heineken faz anúncio machista & Mídia \\
\hline \multirow[t]{2}{*}{ Zero Hora } & \#pitacosdacopa: leitores comentam os jogos da Copa & Esporte \\
\hline & Repercussão da morte de Fernandão & Esporte \\
\hline
\end{tabular}

Fonte: Autoria Própria.

As temáticas também foram analisadas pelo enfoque da manchete. Por exemplo, na manchete de Veja "Os tuites de Miguel Nicolelis" a análise considerou que a história falará sobre os tuites que o cientista brasileiro Miguel Nicolelis trocou com os colunistas da revista, e não sobre 
a sua pesquisa. Por isso, ela está enquadrada na categoria tecnologia. Já na manchete "Internautas repercutem exoesqueleto", de O Estado e São Paulo, a temática em foco é a discussão a respeito da pesquisa de Miguel Nicolelis, por isso, a classificação como ciência.

Era de se esperar que existissem mais temáticas relacionadas ao esporte, já que o recorte temporal inclui a preparação e os primeiros dias da Copa do Mundo no Brasil. No caso do jornal "Zero Hora", contudo, o tratamento exclusivo da temática esporte nesse período ilustra o agendamento, já que outros fatos importantes ocorreram na mesma época, como a corrida da campanha presidencial, fato não retratado por nenhum dos veículos analisados.

O jornal o "Estado de São Paulo" foi o que mais utilizou a ferramenta, trazendo maior variedade de temas. Contudo, das 16 manchetes, cinco falavam sobre a repercussão da greve no metrô. Neste caso, seria necessária uma análise mais aprofundada nas fontes utilizadas para verificar um possível viés político na abordagem do tema.

A revista "Veja" considerou que neste período a notícia de maior relevância foi a troca de mensagens não amigáveis entre os seus colunistas e o cientista brasileiro Miguel Nicolelis. Neste caso, além de uma de uma análise mais aprofundada no texto, é sugerida uma análise dos critérios de noticiabilidade da revista no Storify. Já que, por mais que o exoesqueleto de Nicolelis esteja relacionado à abertura da Copa do Mundo, a manchete preferiu se concentrar na troca de mensagens entre o cientista e os colunistas de Veja.

\section{CONSIDERAÇÕES FINAIS}

A análise das temáticas mais frequentes permitiu concluir que existiu agendamento das notícias na temática cidade, principalmente nas que se referiram à greve do metrô de São Paulo. Foi considerado que não será possível concluir a respeito de agendamento em torno da temática esporte, já que o período escolhido antecedeu em três semanas e coincidiu em três dias com a realização da Copa do Mundo no Brasil, para concluir o sobre o assunto seria necessário uma pesquisa de critérios de noticiabilidade.

A maior parte das manchetes analisadas trazia um balanço da discussão dos internautas a respeito de determinado assunto - do exoesqueleto de Nicolelis, da greve no metrô, da abertura da copa, entre outros - fator que caracteriza uma das funções do Storify, utilizar a inteligência coletiva para contextualizar uma história. Porém, ainda é preciso analisar como esses veículos utilizam as fontes e de que maneira constroem a cidadania nos textos, para poder avaliar a real pluralidade de vozes do jornalismo cidadão. Em relação à temática, o jornal O Estado de São Paulo foi, entre os veículos analisados, o mais plural, depois o jornal Zero Hora, e por fim, a revista Veja. 


\section{REFERÊNCIAS}

ANTOUN, H, MAILNI, F. Mobilização Nas Redes Sociais: a narratividade do \#15M e a democracia na cibercultura. XXII Encontro Anual da Compós, Universidade Federal da Bahia, junho 2013. Disponível em: http://compos.org.br/data/biblioteca 1971.pdf . Acesso em 10 de agosto de 2014.

CASTELLS, M. A Sociedade em Rede. 11 ed. São Paulo: Paz e Terra, 2008.

FOSCHINI, A, TADDEI R. Jornalismo Cidadão: você faz a notícia. Coleção conquiste a rede. Disponível em: http://www.livrosgratis.com.br/arquivos livros/ea000098.pdf . Acesso em 11 de agosto de 2014.

GILLMOR, D. We the media: grassroots journalism by the people. California: O' O'Reilly Media Inc, 2004. http://dx.doi.org/10.1145/1012807.1012808

HOLANDA, A, QUADROS C, PALACIOS, M, SILVA, J. Metodologias de pesquisa em Jornalismo Participativo no Brasil. Brazilian Journalism Research, v. 4 n. 2, 2008. Disponível em: http://bjr.sbpjor.org.br/bjr/article/view/164 . Acesso em 11 de agosto de 2014.

JENKINS, H. Cultura da Convergência: Tradução Susana Alexandrina. 2 ed. São Paulo: Aleph, 2009 LAZZARATO, M. Revoluções do capitalismo. Rio de Janeiro: Civilização Brasileira, 2006.

LÉVY, Pierre. Cibercultura: Tradução de Carlos Irineu da Costa. 3 ed. São Paulo: Editora 24, 2010. Inteligência Coletiva: por uma antropologia do ciberespaço. São Paulo: Loyola, 1998.

MALINI, F. Modelos de colaboração nos meios sociais da internet: Uma análise a partir dos portais de jornalismo participativo. XXXI Congresso Brasileiro de Ciências da Comunicação, Universidade Federal do Rio Grande do Norte, setembro 2008. Disponível em: http://www.intercom.org.br/papers/nacionais/2008/resumos/R3-2015-1.pdf. Acesso em 11 de agosto de 2014.

SANTAELLA, L. Culturas e artes do pós-humano: da cultura das mídias à cibercultura. São Paulo: Paulus, 2003. 